\title{
O DESENVOLVIMENTO PROFISSIONAL DE PROFESSORES DE MÚSICA DA EDUCAÇÃO BÁSICA: UM ESTUDO A PARTIR DE NARRATIVAS AUTOBIOGRÁFICAS
}

\author{
The professional development of music \\ teachers of basic education: a study based on \\ autobiographical narratives
}

\author{
el desarrollo profesional de los profesores de \\ música de educación básica: un estudio de \\ narrativas autobiográficas
}

TAMAR GENZ GAULKE

Universidade Federal do Rio Grande do Norte tamargenzgaulke@hotmail.com

\begin{abstract}
Resumo: Este artigo é um recorte de uma tese de doutorado que teve como objetivo compreender como ocorre o processo de desenvolvimento profissional do professor de música a partir da sua relação com a escola de educação básica. As visões conceituais de lugar de Tuan e de Lévy e Lussault, de desenvolvimento profissional de Nóvoa, e de construção biográfica de Delory-Momberger, bem como a pesquisa autobiográfica, constituem o referencial teórico-metodológico da pesquisa. $\mathrm{O}$ estudo foi realizado com entrevistas narrativas de quatro professores licenciados e atuantes na educação básica. A análise indicou que o desenvolvimento profissional de cada professor é único e pessoal, constituído por meio das experiências. O outro, o eu e a construção do eu com o outro - o lugar - são os eixos que sustentam o desenvolvimento profissional dos professores. Portanto, se reconhecer na experiência na e com a escola é condição do desenvolvimento profissional do professor de música, sendo a experiência com o lugar o que constitui a toca (ethos), a sua morada. A toca é um lugar interno de formação que, ao amalgamar formação pessoal e profissional, se torna lugar promotor do desenvolvimento profissional.
\end{abstract}

Palavras-chave: Desenvolvimento profissional de professores de música. Relação professor e escola de educação básica. Narrativas autobiográficas.

\begin{abstract}
This article is part of a doctoral thesis whose objective was to understand how the process of professional development of music teacher occurs from its relation with the school of basic education. The conceptual view of place of Tuan and Lévy and Lussault, of the professional development of Nóvoa and the biographical construction of Delory-Momberger, as well as the autobiographical research, constitute the theoretical-methodological reference of the research. The study was carried out with narrative interviews of four licensed teachers and active in basic education. The analysis indicated that the professional development of each teacher is unique and personal, constituted through the experiences. The other, the self and the construction of the self with the other - the place - are the axes that sustain the professional development of teachers. Therefore, to recognize oneself in the experience in and with the school is a condition for the professional development of the music teacher, and the experience with the place constitutes the toca (ethos), its dwelling. Toca is an internal place of formation, which, by amalgamating the personal and professional formation, becomes a promoter of professional development.
\end{abstract}

Keywords: Professional development of music teachers; Teacher-school relationship; Autobiographical narratives.

Resumen: Este artículo es un extracto de una tesis doctoral que objetivó comprender cómo ocurre el proceso de desarrollo profesional del profesor de música por médio de su relación con la escuela de educación básica. Las visiónes conceptuales del lugar de Tuan y Lévy y Lussault, de desarrollo profesional de Nóvoa, y de construcción biográfica de Delory-Momberger biográfica, así como la investigación autobiográfica, constituyen el marco referencial teórico-metodológico en la investigación. El estudio se llevó a cabo por entrevistas de narraciones de cuatro profesores con licenciatura y activas en la educación básica. El análisis indicó que el desarrollo profesional de cada docente es único y personal, compuesto de experiencias. El otro, el yo y la construcción del yo con el otro - el lugar - son los ejes que apoyan el desarrollo profesional de los docentes. Por lo tanto, reconocerse en la experiencia en la y con la escuela es una condición del desarrollo profesional del profesor de música, siendo la experiencia con el lugar, lo que constituye la guarida (ethos), su lugar de morada. La guarida es un lugar de formación interna que, para amalgamar la formación personal y profesional, se convierte en un lugar promotor de desarrollo profesional.

Palabras clave: Desarrollo profesional de los maestros de música, correlación entre el profesor y la escuela de educación básica, narrativas autobiográficas. 


\section{INÍCIO DE UMA TRAJETÓRIA}

O caminho que me levou a definir o desenvolvimento profissional como tema da minha pesquisa de doutorado toma como ponto de partida não só a minha dissertação de mestrado sobre aprendizagem da docência de música (Gaulke, 2013), mas também a história do professor de música que saiu de uma das escolas em que atuava por se identificar mais com outra escola. Esse ponto de partida e as experiências a ele vinculadas me levaram a pensar em espaço/lugar e a perceber como os espaços por onde passei me ajudaram a construir quem eu sou. A partir do diálogo com a literatura, busquei transformar o meu interesse em objeto de pesquisa. Neste artigo, trago um recorte da minha tese de doutorado e as principais descobertas sobre o desenvolvimento profissional de professores de música da educação básica.

O professor só se torna professor na escola, mas, para nela atuar, é preciso passar por uma formação. Tendo em vista a atuação na educação básica, a formação inicial em curso de licenciatura é, necessariamente, parte do processo de desenvolvimento profissional, pois a licenciatura é uma exigência legal e, como tal, propicia ao professor a licença para atuar. Essa formação, como indicam a legislação (Brasil, 2015) e a literatura da área de educação musical (Tourinho, 1995; Bellochio, 2001; Mateiro; Téo, 2003; Beineke, 2004; Figueiredo, 2005; Sobreira, 2008), não deve ser vivida sem referência aos espaços de atuação ou, ainda, sem a vinculação a um espaço. A formação inicial também é parte da bagagem de cada professor e é um dos momentos do processo de desenvolvimento profissional.

No entanto, ao menos na literatura, essas recomendações parecem permanecer ao plano das ideias e não chegar, de fato, a ações. Os textos aqui citados, junto a outros, foram analisados por Macedo (2015) em sua tese, e, a partir dessa análise, a autora percebe que "a aproximação da formação aos campos de atuação parece ser uma tarefa bastante complexa, para a qual os autores não apontam soluções finais" (Macedo, 2015, p. 112).

Este propósito - de se pensar um percurso de formação inicial que esteja vinculado aos espaços de atuação profissional - encontra ressonância nas ideias de autores da área de educação, como Nóvoa (2009) e Zeichner (2010), que propõem princípios orientadores dessa formação.

A formação do professor, entretanto, não se encerra com a formação inicial. Canário (2001) e Marcelo (2009), entre outros autores da área de educação, referem-se à formação do professor como um processo contínuo de desenvolvimento profissional, que combina a formação em nivel superior prévia com a construção e reconstrução cotidiana do saber e do agir profissional no interior da escola, lugar onde se aprende a ser professor, segundo Canário (2001). 
Percebo o desenvolvimento profissional como forma de definir um processo a longo prazo, individual e coletivo, que ocorre no contexto de ensino, nas experiências com a escola que contribuem para o desenvolvimento do professor. É uma construção que provoca um processo interativo e dinâmico a partir da relação do professor com a escola.

São as experiências resultantes da relação do professor com a escola que entendo como parte do desenvolvimento profissional e como o foco deste trabalho. A literatura de educação musical e também as Diretrizes Curriculares Nacionais para a formação inicial em nivel superior e para a formação continuada (Brasil, 2015) enfatizam a necessidade de vínculo com o espaço de atuação. Mas como se dá essa relação?

Conforme sintetiza Macedo (2015, p. 147), "ainda são poucos os trabalhos que buscam conhecer o que os professores pensam, como agem em sala de aula e como organizam seu trabalho". Ou ainda, como indica Del-Ben (2013), a escola, na literatura da área de educação musical, tem estado "invisivel".

A partir de levantamento e análise de trabalhos publicados na Revista da Associação Brasileira de Educação Musical (ABEM) sobre os modos de pensar a educação musical escolar, Del-Ben (2013) indica que as especificidades da escola não estão sendo contempladas pela literatura que ela analisou.

[...] Embora mais da metade dos artigos analisados se caracterize como pesquisa empírica, que se aproxima dos sujeitos escolares, eles parecem pensar e agir num lugar ainda pouco estudado, já que as escolas, como instituição, assim como os sistemas educativos em que estão inseridas, estão praticamente ausentes dos artigos analisados. A educação musical escolar é pensada sem considerar as particularidades do lugar em que acontece ou em que se espera que aconteça. As particularidades existem, tanto que se argumenta ser necessário aproximar os cursos de formação e os futuros professores dos contextos escolares, mas não são explicitadas ou analisadas em profundidade [...]. A escola, embora sempre presente, é um espaço que parece invisivel na produção analisada. Mesmo assim, precisa ser transformada (Del-Ben, 2013, p. 142).

A literatura da área de educação musical parece considerar a escola mais "como uma espécie de cenário, de segundo plano sobre o qual se desenrolam suas existências" (Delory-Momberger, 2012, p. 66), ou, mais especificamente, a atividade docente. Essa concepção da escola reduzida a um pano de fundo parece não dar conta da complexidade da dimensão espacial das experiências docentes. Tratar o espaço escolar apenas como uma generalidade ou, simplesmente, deixá-lo em "segundo plano" pode podar-nos da compreensão da escola como um lugar constituído de relações e experiências humanas, como um lugar de formação/autoformação, de 
construção de conhecimentos profissionais - de desenvolvimento profissional. Essa invisibilidade da escola pode comprometer a compreensão da escola como espaço de desenvolvimento profissional.

Todas essas leituras me levaram a definir como objetivo geral desta pesquisa compreender como ocorre o processo de desenvolvimento profissional do professor de música a partir da sua relação com a escola de educação básica. Esse objetivo se desdobra nos seguintes objetivos específicos: identificar experiências de vida e formação que foram significantes para os professores de música se tornarem professores da educação básica; reconhecer experiências construídas na relação do professor de música com a escola de educação básica; entender as experiências na e com a escola que os professores de música significam no seu processo de desenvolvimento profissional.

\section{CONSTRUÇÃO DO MAPA TEÓRICO}

Para aprofundar o entendimento de escola, não somente como um "segundo plano", busquei entender os significados de espaço e de lugar. No âmbito da geografia, esses termos recebem significados diferentes, porém não são conceitos contraditórios. Foi a partir dos estudos da geografia humanista (ou humanística) que os termos foram sendo cuidadosamente diferenciados. Lévy e Lussault (2003, p. 560) diferenciam espaço e lugar, afirmando que lugar é um "espaço em que a distância é irrelevante. A caracterização de um espaço como lugar é o resultado de uma construção". Para Tuan (1983, p. 6):

[...] o espaço seria qualquer porção da superficie terrestre, ampla, desconhecida, temida ou rejeitada e provocaria a sensação de medo, sendo totalmente desprovido de valores e de qualquer ligação afetiva. Neste contexto, o lugar está contido no espaço, "espaço" é mais abstrato que "lugar". O que começa como espaço indiferenciado transforma-se em lugar à medida que o conhecemos melhor e o dotamos de valor.

Para Tuan (1975, p. 152), o "lugar é um centro de significados construído pela experiência", "é criado pelos seres humanos para os propósitos humanos" (Tuan, 1975, p. 160), ou, ainda, conforme Leite (1998, p. 10), o "lugar é principalmente um produto da experiência humana".

Entendo o lugar como uma construção social, imbuída de valores e significados, constituída da experiência que temos do mundo. Como lugar, a escola não representa somente uma construção física ou um espaço utilizado para o ensino e a aprendizagem, a escola é constituída pela experiência humana. 
Viñao (1993-1994, p. 17) afirma, incialmente, que o espaço e o tempo são fundamentais no aprender docente, são elementos básicos da ação educativa.

Qualquer atividade humana precisa de um espaço e um tempo determinados. Assim sucede com o ensinar e aprender, com a educação. Assim, esta, a educação, possui uma dimensão espacial e de aqui que, portanto, também o espaço é, junto com o tempo, um elemento básico, constitutivo, da ação educativa.

Em continuação, o autor reconhece e descreve a transformação desse espaço em lugar e a importância desse acontecimento.

A ocupação do espaço, sua utilização, presume sua constituição como lugar. O "salto qualitativo" do espaço ao lugar é, pois, uma construção. O espaço se projeta ou se imagina, o lugar se constrói. Constrói-se "a partir do fluir da vida" (apud Alba, 1984) e a partir do espaço como suporte; o espaço, por conseguinte, está sempre disponivel e disposto para converter-se em lugar, para ser construído (Viñao, 1993-1994, p. 18).

Considerando a escola um lugar, apresento a seguir a construção biográfica como um caminho de entendimento da relação entre espaço e lugar e de acompanhamento do desenvolvimento profissional do professor de música que ocorre na escola.

Cada sujeito é construído por uma pluralidade de lugares que se fixam nele a partir da ancoragem em cada espaço, e isso passa a fazer parte dele a partir da sua ação individual. Como Delory-Momberger (2012, p. 74-75) afirma, "[...] no lugar onde estamos, trazemos conosco e vivemos uma pluralidade de lugares".

O lugar/espaço ${ }^{1}$ é entendido por Delory-Momberger (2012, p. 67-68) a partir de três sentidos: primeiro, em um "[...] sentido mais material: edifícios, disposições e equipamentos de toda espécie, vias de comunicação, objetos"; segundo, em um sentido onde "[...] o espaço é formado de todas as funções, de todas as representações e de todos os valores que lhe são atribuídos pelo tecido cultural, pelo sistema de organização social no qual ele está inserido"; terceiro, em que:

[...] o espaço é constitutivo da nossa experiência na medida em que nos oferece recursos, em que se encontra aberto à nossa ação e ao nosso pensamento e em que, agimos sobre ele e com ele pela ação e pelo pensamento (DeloryMomberger, 2012, p. 67-68).

\footnotetext{
${ }^{1}$ Cabe ressaltar que o entendimento que a autora transmite para uso da palavra espaço em algumas partes do seu livro é coerente ao sentido em que utilizo o termo lugar.
} 
Posso comparar a um barco que se desloca pelo mar e, em determinados lugares, para e prende sua âncora. Nesse tempo de ancoragem, algas e conchas se grudam no casco, criando um tipo de camada. Toda vez que o barco se desloca, algumas conchas e algas caem, mas outras permanecem e tornam-se parte do barco.

$\mathrm{O}$ barco se deslocou com as conchas e as algas que agora passam a fazer parte dele, mas, a cada nova ancoragem, ele constrói um perfil diferente, que também é um perfil diferente de ação, de deslocamento no mar, pois novas conchas se grudam e fazem, assim, uma diferente marca no percurso do barco. Cada navegar se torna único constituído pela e com a singularidade das suas marcas.

O lugar é construído a partir da nossa experiência. Dos diferentes lugares construímos o nosso lugar, a nossa morada: "Ethos = morada. Ethos = habitat, toca, mas também o fato e a maneira de habitá-la” (Matos, 2006, p. 147, grifos da autora).

Uma toca que pode ser feita somente por nós mesmos, não necessariamente sozinhos, mas como "[...] sujeito que não pode constituir lugar senão em si mesmo e que não pode religar o mundo a não ser na reflexividade e na historicização de sua experiência [...]" (Delory-Momberger, 2012, p. 144, grifos da autora). A minha bagagem é o que forma a minha "toca", a qual carrego para os espaços que frequento. A partir dela, e do que quero e posso colocar nela, é que tomo vestígios da minha experiência com os lugares. Assim, esse lugar passa a fazer parte da minha construção biográfica.

\section{CAMINHOS METODOLÓGICOS}

Utilizei a pesquisa autobiográfica como caminho metodológico para compreender os significados daquilo que o indivíduo narra de sua história. Conforme Delory-Momberger (2011, p. 524),

O objeto da pesquisa biográfica é explorar os processos de gênese e de devir dos indivíduos no seio do espaço social, de mostrar como eles dão forma a suas experiências, como fazem significar as situações e os acontecimentos de sua existência.

As narrativas autobiográficas foram utilizadas com a intenção de dar visibilidade ao processo de desenvolvimento profissional de professores de música da educação básica. Como forma de narrar o vivido, os professores contaram histórias com as marcas da construção do seu (eu)sujeito professor na relação com a escola.

Por meio da entrevista narrativa, eu, como acolhedora dos relatos de experiências, procurei captar as marcas e vestígios da construção do sujeito com o lugar em que transcorrem suas vivências. No entanto, há, na performance do entrevistado, um processo de reflexão, de dar status de 
experiência às suas vivências. As experiências são construídas a partir do que o entrevistado decide e permite fazer com elas, pois, conforme Larrosa (2002, p. 21),

A experiência é o que nos passa, o que nos acontece, o que nos toca. Não o que se passa, não o que acontece, ou o que toca. A cada dia se passam muitas coisas, porém, ao mesmo tempo, quase nada nos acontece. Dir-se-ia que tudo o que se passa está organizado para que nada nos aconteça.

Portanto, esta pesquisa busca "ver o mundo" a partir do sujeito, reconhecendo a existência de representações e valores construídos fora do sujeito em si, mas abordando-os a partir do que cada professor faz com eles. Nesta pesquisa, construo os significados e significações do desenvolvimento profissional com o olhar voltado para o sujeito, para o professor, para a sua percepção, para a sua experiência.

Para as entrevistas, foram escolhidos quatro professores experientes de Porto Alegre/RS, licenciados e que estivessem atuando na educação básica há mais de cinco anos. Ao entrevistar as professoras Martha, Clara e Clarice e o professor Jorge, busquei conduzir e estabelecer uma espécie de diálogo, em que me mostrava interessada pelo narrar de suas experiências. Nesse processo, os entrevistados foram narrando suas vivências, dando significado a elas, constituindo-as em experiências e, por meio desse exercício de lucidez, organizavam e reorganizavam sua trajetória de desenvolvimento profissional.

Martha tem 52 anos, trabalha há 21 anos como professora de música da educação básica e em 2003 entrou por concurso na Rede Municipal de Ensino, onde continua trabalhando como professora de música.

Jorge tem 30 anos, trabalha na educação básica há oito anos como licenciado em música e está continuamente envolvido com diferentes atividades artístico-musicais. O seu trabalho na escola foi encaminhado a partir do estágio que fez no curso de licenciatura em música no ano de 2006. Jorge trabalha em duas escolas municipais: em uma delas como professor voluntário de violão e, na outra escola, como professor concursado, trabalha 20 horas no projeto de música.

Clara tem 32 anos e trabalha há nove anos como professora de música em escolas de educação básica. Em 2008, Clara passou no concurso para professora de música de uma escola pública e ainda hoje trabalha nessa escola 40 horas com dedicação exclusiva.

Clarice teve a formação no curso superior quase paralela à prática de ensino de música, pois começou a trabalhar como professora aos 21 anos, ainda durante o curso de bacharelado em piano. Clarice tem 44 anos e, em agosto de 2015, completou 17 anos de trabalho em uma mesma escola privada. 
$\mathrm{Na}$ análise, por meio das narrativas e com base nos princípios da teoria fundamentada apresentados por Strauss e Corbin (2008) e Charmaz (2009), procurei mostrar como se produzem as experiências dos professores com e na escola de educação básica e a forma como elas se complementam sem ter uma estrutura fixa, mas como uma maneira possivel de ilustrar os sentidos do trabalho do professor de música na escola. Com o princípio de preservar a história dos sujeitos, pretendi compreender as experiências em busca de uma possivel generalização analítica (Abrahão, 2003).

Neste artigo, optei por trazer a narrativa da minha experiência com os dados da pesquisa. Não apresentarei a narrativa dos professores entrevistados, mas, sim, o meu processo de construção da análise das narrativas dos professores e minhas considerações.

\section{SOBRE AS EXPERIÊNCIAS NARRADAS PELOS PROFESSORES}

O processo de desenvolvimento profissional dos professores de música na escola de educação básica se ramifica em três dimensões principais: do trabalho na escola de educação básica; da relação com os sujeitos escolares - o outro; da autoformação.

Pensando em um processo de desenvolvimento profissional, procurei correlacionar as categorias imaginando um ciclo de desenvolvimento, em que cada etapa (não necessariamente temporal) conduz a uma outra, culminando numa categoria sintese, ou aglutinadora, dos fenômenos que compõem o processo de desenvolvimento.

\section{Do trabalho na escola de educação básica}

As narrativas dos professores se desenrolaram em trajetórias de vida profissional vividas junto com a escola. Na relação com a escola de educação básica, os professores, ao conscientizarem-se da dinâmica de ensinar, evidenciaram disposição para aprender com os alunos na prática, na realidade em que se encontravam, e constituírem-se por meio desse lugar. Foi a escola que fez dos professores ensinantes e aprendizes, e foi a prática na sala de aula que pôde mostrar caminhos para que pudessem aprender e, assim, conseguissem se vincular a esse espaço.

Um aspecto central do desenvolvimento profissional dos professores é o trabalho na escola - um lugar de experiências, de desenvolvimento da profissão na prática e da construção do saber-fazer -, entendido como meio pelo qual ocorre a construção do ser professor, do reconhecer-se e do ser reconhecido. Compreendo o trabalho do professor na escola de educação básica por meio de três subdimensões: da função do professor de música na escola, das rotinas e sentidos do ensino, da satisfação e realização com o trabalho. 


\section{Da função do professor de música na escola}

Os professores indicaram a necessidade de reconhecer sua função como professor de música. É importante que o professor se reconheça na escola para que nela permaneça e consiga trabalhar. Reconhecer-se no ambiente escolar está atrelado ao reconhecimento da função de professor, de modo geral, e da função de professor de música, em específico. Há um processo de entendimento, da parte do professor, de sua função na escola, no qual ele compreende o que ele faz naquele espaço, o que lhe compete como professor de música.

Entendo o reconhecimento da função também como um autorreconhecimento na profissão. É um processo de entender "quem eu sou como profissional", perceber o que compete à função, mas, também, como eu me vejo como profissional, como eu me reconheço nessa profissão. Compreendo como um insight na profissão a percepção da pessoa do professor como um profissional que tem funções em uma determinada escola, funções cujo "jeito" de realização pode ser determinado pelo próprio professor. Os professores se definem e definem sua função em relação a este espaço específico que é a escola.

Para além do processo de reconhecer-se como profissionais, os professores indicam lidar com questões deontológicas do exercício da profissão, correspondentes à sua relação com alunos, familiares e outros professores.

Essas questões colocam em confronto o conjunto de deveres e regras de natureza ética de sua classe profissional. No entanto, apesar de tratarem desse assunto ao longo de suas narrativas, os professores, com o passar do tempo, foram encontrando soluções para lidar com exigências que ultrapassassem o que eles entendiam que fazia parte de suas funções. Também sustentam em suas narrativas que, no decorrer de sua atuação na escola, seu compromisso está relacionado com a formação humana.

\section{Das rotinas e sentidos do ensino}

Por entender a sua função como profissional, ele passa a se reconhecer como um professor na e da escola, construindo significados da sua relação com o espaço, tornando-o lugar. O lugar é construído pelas experiências; ao mesmo tempo, as experiências com esse lugar fazem parte da constituição do professor. Com isso, cada professor consegue se integrar e pertencer ao coletivo, sentindo-se profissional e pertencente à categoria profissional.

Em suas narrativas, os professores contaram sobre suas rotinas e condições de trabalho nas escolas, sobre os modos de organização do trabalho e, principalmente, como isso influencia na prática e no sentido do seu trabalho como docente. Os professores relataram saber o que querem para a escola, o sentido do próprio trabalho e como, a partir disso, vão construindo coisas, descartando ideias e práticas. 
Entendo que o desenvolvimento profissional depende do reconhecimento da profissão. Reconhecer-se profissionalmente, entender que faz parte de uma categoria profissional e compreender em que consiste a sua profissão mostrou-se fundamental para que cada professor continuasse na escola e continuasse se construindo como professor. Esse reconhecimento está relacionado ao ser reconhecido no papel de professor, conquistar o reconhecimento de sua profissão por parte de outras pessoas. Percebo que o reconhecimento da profissão e o reconhecimento do outro são como uma marca, uma espécie de ancoragem e afirmação do professor na sua profissão e, concomitantemente, na escola em que passa a se reconhecer.

O pertencimento do professor a esse coletivo, a essa escola, está atrelado ao bem-estar na escola, ao sentir-se bem no espaço e ao fato de ser reconhecido pelo seu trabalho. O professor atua na escola oferecendo-lhe algo. Essa oferta passa por negociação e adaptação e direciona o professor a fazer parte do coletivo. Sentindo-se pertencente, o professor se realiza com o seu trabalho, e isso funciona como um alimento para a sua permanência na escola, como uma troca.

O desenvolvimento profissional acontece quando o professor consegue dar um sentido para o seu trabalho. O sentido do trabalho é uma alavanca do desenvolvimento profissional. No entanto, esse sentido do trabalho não está relacionado somente ao que o professor sente da sua atuação, nem ao entendimento do trabalho como uma missão para o professor, mas, sim, aos diversos sentidos atribuídos pelos professores, incluindo o sentido para o outro, a percepção de que o seu trabalho é significativo para os outros, a percepção de que esse trabalho se cumpre com um sentido.

\section{Da satisfação e realização com o trabalho}

Os professores, ao narrarem suas experiências, reconheceram a necessidade de perceber que estar na escola os alimenta e os realiza pessoal e profissionalmente. Tornando a atividade profissional na escola recompensadora para si e para os outros, os professores passam a se alimentar da própria prática, construindo um processo de desenvolvimento profissional próprio, embasado na relação com o espaço, significando-o e constituindo-o como lugar.

O reconhecimento do trabalho é narrado pelos professores por meio das demonstrações de afeto e carinho dos alunos, do retorno dos colegas professores e da direção - os sujeitos escolares -, da realização do professor com as aprendizagens dos alunos e com o próprio crescimento pessoal, que também abrange a relação com o outro. Isso atravessa o professor, constituindo-se experiência e nutrindo-o de motivos para continuar com sua atuação naquele lugar. Saber o que está fazendo na escola e saber que isso faz sentido levam o professor a conquistar o seu espaço e permanecer na escola. 
Bowman (2012), citando Higgins, salienta que a atividade de ensino do professor não pode ser concebida de modo altruísta, pois deve compreender também a realização pessoal que os professores buscam com o ensino. Fica claro que o querer permanecer na escola está ligado ao retorno e à satisfação que a prática proporciona aos professores. O lugar precisa dar algo em troca, como um alimento que nutre o desejo de ficar nessa escola. Saber o que está fazendo na escola e saber que isso faz sentido leva o professor a conquistar o seu espaço e permanecer na escola.

Os professores buscam respeitar os alunos dentro da escola e mostrar que todos eles são importantes no mundo. Eles se ligam aos indivíduos, buscando uma relação produtiva, que promove uma disposição para ficar nesse lugar. O afeto entre professores e alunos tem forte presença no discurso dos professores. Por parte dos professores, há uma preocupação com a formação humana. Saber da experiência dos alunos e do significado das aulas de música para eles é algo que atravessa os professores e os transforma. O desafio de trabalhar com o diferente, com o outro, faz com que os professores revejam e descartem práticas, conceitos e ideias, para que possam se aproximar dos alunos nas aulas de música.

\section{Da relação com os sujeitos escolares - o outro}

As narrativas dos professores sinalizam um entendimento do ensino como encontro humano e como responsabilidade pelo outro. É na alteridade que o professor se desenvolve profissionalmente. É na relação com o outro, na presença pública, que o professor se coloca em movimento de ensino e aprendizagem. Também é na relação com os sujeitos escolares que o professor desenvolve o seu trabalho. Ele ensina algo para alguém e, por isso, entendo que a formação inicial não tem como antecipar ou abreviar o desenvolvimento profissional, pois ele só ocorre na alteridade, no perceber o outro, no confrontar-se e confortar-se com esse outro.

Ao reconhecer as experiências construídas junto com os outros, os professores se nutrem dessas relações, incluindo a realização dos alunos com as aulas de música, e as tornam experiências recompensadoras na profissão (Bowman, 2012). Eles reconhecem a necessidade de perceber que estar na escola os alimenta e os realiza pessoal e profissionalmente. Tornando a atividade profissional na escola recompensadora para si e para os outros, os professores passam a se alimentar da própria prática, construindo um processo de desenvolvimento profissional próprio, embasado na relação com o espaço, significando-o e constituindo-o como lugar.

Os professores carregam consigo o seu jeito na construção do seu trabalho na escola. Como um barco no mar, em que diversas conchas se prendem e se soltam, cada professor, na escola, parece lidar com um conjunto diverso de conchas que também vêm ao encontro do seu barco, deixando marcas. Assim como o barco, eles vão ao encontro dos alunos, que 
também vêm ao encontro dos professores. É por meio desse encontro que esses diferentes jeitos se acomodam e se acumulam.

\section{Da autoformação}

Nesse processo de desenvolvimento profissional, ocorre uma configuração profissional do professor (Nóvoa, 1992), que está relacionada à construção do professor como profissional, mas, também, diretamente ligada à dimensão pessoal do professor. A partir disso, percebi que esse lado pessoal se configura ao mesmo tempo que o lado profissional, pois é na presença pública do professor no espaço da escola que é promovida a configuração pessoal. O professor coloca-se como pessoa ao se relacionar com o outro, tornando-se presente publicamente para exercer a profissão e, assim, vai configurando-se pessoal e profissionalmente. O lado pessoal molda o lado profissional, enquanto o profissional reconstrói o pessoal, pois os professores partem do pessoal (suas crenças, valores, experiências) para definir o profissional quando chegam nas escolas. Posteriormente, a partir da relação com o outro, vão modificando o profissional e se transformando ou se alimentando pessoalmente.

Ao assumirem os seus jeitos, suas crenças e acreditarem em si como professores que ensinam e aprendem, os professores conseguem deixar algumas práticas de lado, esculpindo-se como professores conforme o lugar em que estão. A segurança, que nasce do tempo de prática na escola, também permite a alguns professores "desdizerem" teóricos e construírem conhecimentos próprios. A partir disso, percebo uma disposição desses professores para reconhecerem-se e serem reconhecidos como profissionais.

Relembro que o próprio professor é o determinante para o seu desenvolvimento, é ele o autor de sua própria história na e com a escola. A escola e a sala de aula tornam-se um local de prática formativa. Desse modo, a escola não pode ser tratada como simples pano de fundo. A experiência adquirida na prática na escola é o próprio respaldo para o professor do seu trabalho, e, por meio disso, ele mesmo acompanha o movimento constante de configuração profissional (Nóvoa, 1995), utilizando a avaliação de sua prática para repensar-se como professor.

Portanto, compreendo a atuação na escola como formação do professor, não como uma formação única nem como formação continuada, mas, sim, como aquilo que faz ele ser quem ele é na escola. A atuação constitui-se em experiência quando é avaliada, analisada, refletida. A experiência é a produção do saber da prática; assim, a experiência, como biografização, é condição para o saber-fazer.

Somente na prática que se é professor, ou seja, a condição para o desenvolvimento na profissão é a atuação do professor. Assim, entendo que a própria atuação é formação, direcionando para uma autoformação. Entender a atuação como formativa é uma tentativa de amalgamar formação 
e atuação, o que não significa que a formação inicial seja desnecessária, como claramente indicam alguns dos professores entrevistados, nem que a atuação, em si, seja suficiente para que o professor se desenvolva profissionalmente.

\section{CONSIDERAÇÕES AO FINDAR DA TRAJETÓRIA}

A interpretação das narrativas autobiográficas dos professores de música da educação básica me permite destacar os eixos que sustentam o desenvolvimento profissional dos professores: o outro, o eu e a construção do eu com o outro - o lugar. O outro remete à alteridade presente no desenvolvimento profissional e a ele necessária. É a partir do outro que o professor constrói um sentido da profissão e se depara com as questões deontológicas, e, também, edifica o reconhecimento do trabalho do professor. O eu está relacionado à dimensão pessoal do professor, ao reconhecimento de si como pessoa e como profissional, à satisfação com o trabalho e ao crescimento que vem com a atuação. O eu e o outro são as peças-chave que constituem o lugar. O lugar, aqui, é a síntese da relação do eu com o outro.

Retomo a simbologia do barco no mar como uma forma de ilustrar o entendimento da autoformação. Considero a atuação, entendida como autoformação, parte fundamental do processo de desenvolvimento profissional do professor. É o professor que, com sua vontade e energia, atua na escola. É como o condutor do barco, que o aciona, ou levanta a vela, para fazer o barco movimentar-se no mar.

A partir da sua atuação na escola, o professor também consegue desenvolver o entendimento da sua função como professor nesse lugar, como um barco no mar que reconhece o seu caminho ao percorrê-lo. Pode haver uma ideia anterior do traçado do caminho, assim como o conhecimento de alternativas do que será encontrado nesse caminho, mas, ao percorrê-lo com o barco, o condutor reconhece o trajeto ou, antes, passa a conhecê-lo. Por meio da atuação, do entendimento da função e das experiências do professor, ocorre o reconhecer-se como professor. O reconhecer-se faz, fundamentalmente, o professor ir adiante, mover-se profissionalmente, por também conseguir se perceber como profissional.

Assim como o condutor do barco conhece e reconhece seu trajeto, ele também passa a ser reconhecido pelo mar, pelos peixes, pelas algas, por aquilo que o próprio barco encontrar no caminho. Esse reconhecimento pode se dar pela abertura para a passagem do barco ou mesmo pelo fato desses elementos identificarem o barco como morada, passando a fazer parte desse ambiente. O professor também passa a ser reconhecido na escola como sujeito, parte do lugar da escola, no qual se move atuando, entendendo e reconhecendo-se como professor. E, ao se vincular ao espaço, tornando-o lugar, também consegue sentir-se parte do coletivo, da categoria 
profissional professor, que o ajuda a dar um possivel rumo ao desenvolvimento profissional.

O professor, constituído de suas experiências, é quem conduz o seu desenvolvimento profissional na escola. Assim como o condutor do barco provoca o movimento desse barco em um mar desconhecido, ou que está em constante modificação, por também estar em movimento, o professor conduz, provoca e realiza seu desenvolvimento profissional na produção de suas experiências: sua autoformação. Sendo assim, compreendo que esse processo, constituído de movimentos e ancoragens - como momentos de lucidez constitutivos da experiência - no tempo e espaço da escola, é o que compõe o desenvolvimento profissional do professor de música da educação básica. As ancoragens fixam o barco, mas, ao mesmo tempo, o levam a se reconstruir por meio do que se prende no seu casco durante esse tempo e nesse espaço. Portanto, entendo que o professor, como pessoa constituída de diversas experiências, é quem percorre esse processo único e pessoal. Acredito que o lado pessoal do professor - com suas bagagens experienciais - influencia e maneja o lado profissional, pois o professor é a pessoa que conduz a si mesma para se desenvolver profissionalmente. O barco no mar ilustra o processo de desenvolvimento profissional no tempo e no espaço.

Apesar de a trajetória do barco indicar algo linear, em um tempo cronológico, as ancoragens, de alguma forma, rompem ou estancam a linearidade simbolizando o tempo biográfico, porque o barco para, mas a água continua em movimento. As conchas podem cair ou se grudar com o barco parado, pois a água ainda está em movimento, o que indica a interferência do que está fora do sujeito, ou do que não nasce a partir da ação, do movimento do sujeito professor. No entanto, apenas essa simbologia não parece dar conta desse lado pessoal e da sua relação com o lado profissional.

Entendo a dinâmica do processo de desenvolvimento profissional a partir da constituição de uma toca (ethos), da sua morada, em que o professor constrói lugar em si mesmo, constituindo-se biograficamente a partir da escola (lugar). A toca, sendo própria, pertencente e viva no professor, é um certo lugar interno que proporciona o desenvolvimento profissional e a sua permanência na escola.

O barco é sempre apresentado em movimento, em processo. A toca, por mais que seja algo sempre sendo construído, em construção, dá ideia de algo mais fixo, que está ancorado internamente. O barco se desloca; a toca é o porto seguro, embora não seja um porto estático ou fixo; é a segurança ou estabilidade que permite que o barco continue em movimento. A toca dá estabilidade para que o barco possa continuar saindo em viagem. Para continuar conduzindo o barco, o sujeito precisa perceber que a toca começa a se configurar (ela também estará sempre em construção, mas é preciso que tenha um começo). A toca é o porto seguro, que é tanto ponto de partida 
quanto ponto de chegada, nunca está no mesmo lugar, mas, ao mesmo tempo, sempre está num lugar seguro, que é o próprio sujeito.

A toca sugere um tempo interno (kairós), e não mais cronológico (chronos). No entanto, o desenvolvimento profissional também precisa do tempo cronológico (externo), os professores não escapam desse tempo externo, e é esse o tempo que proporciona o encontro entre o sujeito professor e os outros sujeitos, é o tempo comum entre eles. O professor como barco e os outros sujeitos (alunos, outros professores, tecido cultural etc.) como água, conchas e algas.

$\mathrm{Na}$ toca, em um tempo e espaço/lugar, o professor guarda suas bagagens, suas memórias experienciais, que passam a constituí-lo como pessoa e como professor. As experiências constituídas pelo professor na sua atuação somam-se às suas bagagens anteriores e levam o professor a organizar e reorganizar seus saberes experienciais, gerando novos saberes e consolidando outros. A toca é a amálgama do lado pessoal com o lado profissional. Constitui um lado profissional "pessoalizado"; é pessoal porque é construído pelo sujeito, mas profissional na sua natureza: um conhecimento profissional da pessoa.

A toca é um "terceiro lugar", onde se dá a vinculação entre o lado pessoal e o lado profissional; a vinculação entre o (eu)sujeito e o trabalho. Mas a vinculação, para configurar a toca, também precisa ser formativa; a vinculação precisa trazer outras ou novas formas, precisa transformar ou mudar a forma anterior de algum modo, seja a forma do pessoal, seja a forma do profissional. A toca é, assim, um lugar interno de formação que, ao amalgamar formação pessoal e profissional, se torna lugar promotor do desenvolvimento profissional.

\section{REFERENCIAS}

ABRAHÃO, Maria Helena Menna Barreto. Memória, narrativas e pesquisa autobiográfica. História da Educação, ASPHE/FaE/UFPel, Pelotas, v. 7, n. 14, p. 79-95, 2003.

BEINEKE, Viviane. Politicas públicas e formação de professores: uma reflexão sobre o papel da universidade. Revista da ABEM, Porto Alegre, v. 10, p. 35-41, 2004.

BELLOCHIO, Cláudia Ribeiro. Educação musical: olhando e construindo na formação e ação de professores. Revista da ABEM, Porto Alegre, v. 6, p. 4148, 2001.

BOWMAN, Wayne. Practices, Virtue Ethics, and Music Education. Action, Criticism, and Theory for Music Education, v.11, n. 2, p. 1-19, 2012.

Disponivel em:

http://act.maydaygroup.org/articles/Bowman11_2.pdf. Acessado em: 22 out. 2015. 
BRASIL. CONSELHO NACIONAL DE EDUCAÇÃO. Conselho Pleno.

Resolução CNE/CP 2/2015. Define as Diretrizes Curriculares Nacionais para a formação inicial em nivel superior (cursos de licenciatura, cursos de formação pedagógica para graduados e cursos de segunda licenciatura) e para a formação continuada. Diário Oficial da União, Brasília: Seção 1, p. 8$12,2015$.

CANÁRIO, Rui. O papel da prática profissional na formação inicial e continua de professores. In: CONGRESSO BRASILEIRO DE QUALIDADE NA EDUCAÇÃO FORMAÇÃO DE PROFESSORES, 2001. Anais [...]. Brasília: MEC - Secretaria de Educação Fundamental, 15-19 out. 2001. Disponivel em: http://portal.mec.gov.br/seb/arquivos/pdf/vol1c.pdf. Acesso em: 14 abr. 2015.

CHARMAZ, Kathy. A construção da Teoria Fundamentada: guia prático para análise qualitativa. Porto Alegre: Artmed, 2009.

DEL-BEN, Luciana. Modos de pensar a educação musical escolar: uma análise de artigos da Revista da ABEM. InterMeio: revista do Programa de Pós-Graduação em Educação, Campo Grande, v. 19, n. 37, p. 125-148, 2013.

DELORY-MOMBERGER, Christine. Fundamentos epistemológicos da pesquisa biográfica em educação. Educação em Revista, Belo Horizonte, v. 27 , n. 1, p. 333-346, 2011.

A condição biográfica - ensaios sobre a narrativa de si na modernidade avançada. Tradução de Carlos Galvão Braga, Maria da Conceição Passeggi, Nelson Patriota. Natal: EDUFRN, 2012.

FIGUEIREDO, Sérgio L. F. Educação musical nos anos iniciais da escola: identidade e politicas educacionais. Revista da ABEM, Porto Alegre, v. 12, p. 21-29, 2005.

LARROSA, Jorge. Notas sobre a experiência e o saber de experiência. Revista Brasileira de Educação, n. 19, 2002.

LEITE, Adriana Filgueira. O Lugar: duas acepções geográficas. Anuário do Instituto de Geociências - UFRJ, v. 21, p. 9-20, 1998. Disponível em: www.anuario.igeo.ufrj.br/anuario_1998/vol21_09_20.pdf. Acesso em: 21 maio 2014.

LÉVY, Jacques; LUSSAULT, Michel. Lieu. In: LÉVY, Jacques; LUSSAULT, Michel (Dir.). Dictionnaire de la géographie et de l'espace des sociétés. Paris: Belin, 2003.

MACEDO, Vanilda Lídia Ferreira de. Imagens da docência de música na educação básica: uma análise de textos da Revista da ABEM (1992-2013). Tese (Doutorado em Música) - Universidade Federal do Rio Grande do Sul, Porto Alegre, 2015. 
MARCELO, Carlos García. Desenvolvimento Profissional Docente: passado e futuro. Sísifo - Revista de Ciências da Educação, Lisboa, v. 8, p. 7-22, 2009. Disponivel em: http://sisifo.fpce.ul.pt. Acesso em: abr. 2015.

MATEIRO, Teresa; TÉO, Marcelo. Os relatórios de estágio dos alunos de música como instrumento de análise dos processos de planejamento. Revista da ABEM, Porto Alegre, v. 9, p. 89-95, 2003.

MATOS, Olgária. Discretas esperanças: reflexões filosóficas sobre o mundo contemporâneo. São Paulo: Nova Alexandria, 2006.

NÓVOA, António. Formação de professores e profissão docente. In: NÓVOA, António (Coord.). Os professores e a sua formação. Lisboa: Dom Quixote, 1992. Disponível em:

http:/ / repositorio.ul.pt/bitstream/10451/4758/1/FPPD_A_Novoa.pdf. Acesso em: 30 jan. 2014.

. Os professores e as histórias da sua vida. In: NÓVOA, A. (Org.). Vidas de professores. Porto: Porto Editora, 1995. p.11-30.

- Professores: imagens do futuro presente. Lisboa: Instituto de

Educação EDUCA, 2009. Disponível em:

http:/ / www.utfpr.edu.br/patobranco/estrutura-

universitaria/diretorias / dirgrad/planejamento-2017-

fevereiro/ProfessoresImagensdoFuturoPresente.pdf. Acesso em: nov. 2015.

SOBREIRA, Sílvia. Reflexões sobre a obrigatoriedade da música nas escolas públicas. Revista da ABEM, Porto Alegre, v. 20, p. 45-52, 2008.

STRAUSS, Anselm L.; CORBIN, Juliet. Pesquisa Qualitativa: técnicas e procedimentos para o desenvolvimento de Teoria Fundamentada. Porto Alegre: ArtMed, 2008.

TOURINHO, Irene. "Atirei o pau no gato, mas o gato não morreu...". Divertimento sobre estágio supervisionado. Revista da ABEM, v. 2, p. 35-52, 1995.

TUAN, Yi-Fu. Place: an experiential perspective. Geographical Review, v. 65 n. 2, p. 151-165, 1975.

. Geografia humanística. In: CHRISTOFOLETTI, Antônio (Org.). Perspectivas da geografia. São Paulo: Difel, 1982.

Espaço e lugar: a perspectiva da experiência. São Paulo: Difel, 1983.

GAULKE, Tamar Genz. Aprendizagem da docência: um estudo a partir de narrativas de professores de música da educação básica. Dissertação (Mestrado em Música) - UFRGS, Porto Alegre, 2013.

ZEICHNER, Kenneth. Repensando as conexões entre a formação na universidade e as experiências de campo na formação de professores em 
faculdade e universidades. Revista Educação, Santa Maria, v. 35, n. 3, p. 479-504, 2010.

Tamar Genz Gaulke é Doutora pela Universidade Federal do Rio Grande do Sul (UFGRS), é docente do curso de Licenciatura em Música da Escola de Música da Universidade Federal do Rio Grande do Norte (UFRN). https://orcid.org/0000-0003-1582-3782 